\title{
UsabiliCity: Um Jogo de Apoio ao Ensino de Propriedades de Usabilidade de Software Através de Analogias
}

\author{
Bruna M. Ferreira ${ }^{1}$, Luis Rivero ${ }^{2}$, Adriana Lopes ${ }^{3}$, Anna Beatriz Marques ${ }^{4}$, \\ Tayana Conte ${ }^{5}$ \\ Grupo de Usabilidade e Engenharia de Software \\ Instituto de Computação - Universidade Federal do Amazonas \\ Manaus - Brasil \\ \{bmf, luisrivero, adriana, anna.beatriz, tayana\}@icomp.ufam.edu.br
}

\begin{abstract}
Usability is one of the key factors of software quality in the software development process. It is necessary that practitioners working in software development learn how to apply usability evaluation methods, such as inspections and user testing, in order to improve the quality and acceptance of the developed software. In order to facilitate the learning process of one of the most applied usability inspection methods, the Heuristic Evaluation - HE, we have developed UsabiliCity. Such game aims at teaching the HE through analogies. Besides presenting the game, this paper describes its development process and its initial empirical evaluation.
\end{abstract}

Resumo. Usabilidade é um atributo de qualidade muito importante no desenvolvimento de software. É necessário que o profissional de computação aprenda o uso de técnicas de avaliação de usabilidade, como inspeção e teste, para garantir a qualidade e aceitação do software desenvolvido. Para facilitar a aprendizagem de uma técnica de inspeção de usabilidade muito aplicada por profissionais de computação, a Avaliação Heurística - AH, foi desenvolvido o UsabiliCity. Este jogo tem como objetivo o ensino da AH através de analogias. Além de apresentar o jogo, este artigo descreve o seu processo de desenvolvimento e avaliação experimental inicial.

\section{Introdução}

A avaliação de usabilidade permite que um avaliador faça um julgamento sobre a qualidade de uso do software desenvolvido (ou seus artefatos), e identifique problemas que possam prejudicar a experiência do usuário (Barbosa e Silva, 2010). Inspeção de usabilidade é um tipo de avaliação de baixo custo e alto benefício onde um inspetor examina a interface verificando se esta respeita propriedades de usabilidade.

O domínio das propriedades de usabilidade a serem consideradas no desenvolvimento de software é uma competência fundamental para o profissional de computação. Ao conhecer estas propriedades, a equipe de desenvolvimento pode projetar e desenvolver sistemas com maior qualidade de uso, diferenciando os seus produtos perante o mercado e aumentando sua aceitação (Fernandez et al., 2011). No entanto, propriedades de usabilidade e/ou técnicas de avaliação de usabilidade raramente são ensinadas como um elemento indispensável do processo de desenvolvimento de 
software (Benitti e Sommariva, 2012). Nesse contexto, faz-se necessário apoiar o ensino de propriedades de usabilidade e técnicas de avaliação na formação dos profissionais.

Uma abordagem para apoiar o ensino de computação e de outras áreas (como história, matemática, literatura, geografia, etc.) é o uso de Serious Games que são jogos cujos objetivos vão além do entretenimento (Vargas et al., 2014). Nesse sentido, a palavra 'sério' se refere ao propósito do jogo e não ao seu conteúdo. Serious Games criam uma competição mental entre o jogador e o computador com regras específicas, e fazem uso do entretenimento para atingir objetivos educacionais (Zyda, 2005). Contudo, os Serious Games existentes para apoiar o ensino de propriedades de usabilidade (Sommariva et al., 2011) não focam em como o aluno pode entender e aplicar melhor os conceitos para identificar problemas que afetem a qualidade de uso de um sistema.

Diante disso, este artigo apresenta o jogo intitulado "UsabiliCity", destinado ao ensino das propriedades de usabilidade descritas na técnica Avaliação Heurística (AH) (Nielsen, 1994), uma técnica muito adotada para inspecionar a usabilidade de aplicações de software (Fernandez et al., 2011). O jogo faz uso de analogias para reforçar os conceitos das heurísticas da técnica $\mathrm{AH}$ e apresenta uma história com o intuito de motivar o aluno durante o processo de aprendizagem. Para obter indícios da viabilidade do uso do jogo UsabiliCity em um ambiente acadêmico, foi executado um estudo experimental inicial. Neste estudo, o jogo foi testado por alunos de um curso de Ciência da Computação, e avaliado em termos da experiência do usuário que o mesmo proporciona. Além disso, o jogo foi avaliado por um professor da área de Interação Humano Computador (IHC), quanto aos requisitos pedagógicos e de usabilidade.

Este artigo está organizado da seguinte forma: na Seção 2, são descritos os trabalhos relacionados com esta pesquisa. Na Seção 3 é descrito o jogo UsabiliCity e a metodologia utilizada para seu desenvolvimento. Além disso, a Seção 4 apresenta a sua avaliação experimental em termos de experiência do usuário e requisitos de usabilidade e pedagógicos. Finalmente, a Seção 5 apresenta as conclusões e trabalhos futuros.

\section{Trabalhos Relacionados}

Segundo An et al. (2013), o ensino está se transformando, pois aulas expositivas têm se tornado insuficientes para atingir o sucesso do aprendizado, sendo indicados trabalhos que favoreçam a interação do aluno. Consequentemente, existe um aumento do interesse para o aprendizado através de jogos, visto que estes propiciam um espaço multissensorial e de intenso envolvimento por parte do aluno (da Silva e Melo, 2013).

Vargas et al. (2014) executaram uma revisão sistemática da literatura sobre jogos sérios, identificando oportunidades de pesquisa. Nesta revisão, os autores identificaram que $24 \%$ dos jogos propostos eram aplicáveis ao ensino de computação, focando em: fundamentos de computação, lógica e programação, sistemas operacionais, engenharia de software e outros. Apesar do aumento do número de jogos para o ensino de computação, segundo Sommariva et al. (2011), o número de jogos para ensino de propriedades e/ou técnicas de inspeção de usabilidade ainda é baixo.

Dentre os Serious Games e ferramentas para o ensino de usabilidade e inspeções podem ser citados: (a) UsabilityGame, (b) InspSoft e (c) Heva. O UsabilityGame é um jogo simulador que aborda aspectos do ciclo de vida de usabilidade (Sommariva et al., 
2011). O jogo tem como cenário uma empresa de desenvolvimento de software fictícia que está contratando engenheiros de usabilidade. Assim, o jogador (aluno) assume o papel de engenheiro de usabilidade e deve buscar um bom desempenho em cada uma das fases do jogo, que possuem relação com as fases do ciclo de vida proposto. Por outro lado, o InspSoft é um jogo educacional voltado para inspeção de software em um documento de especificação, que simula uma situação de inspeção de software em uma empresa de desenvolvimento (Lopes et al., 2013). O objetivo é obter aprendizado sobre os papéis de cada participante no processo de inspeção e os tipos de defeitos que podem ser encontrados em um documento. Finalmente, a Heva é uma ferramenta acadêmica para a prática da técnica de inspeção Avaliação Heurística (Nielsen, 1994), que pode ser utilizada em laboratório por alunos para praticar os conhecimentos (Oeiras et al., 2008).

Apesar de terem sido propostos alguns Serious Games para o ensino de usabilidade e inspeções nos cursos de computação, ainda é necessário fornecer meios de ensinar propriedades específicas de usabilidade como as descritas na técnica Avaliação Heurística (Nielsen, 1994). Além disso, existe uma carência de avaliação experimental dos jogos aplicáveis ao ensino de computação para verificar se os mesmos atendem os requisitos de usabilidade e pedagógicos, e se os mesmos proporcionam uma boa experiência de usuário (Vargas et al., 2014). Tendo em vista este cenário, foi proposto o jogo UsabiliCity que será descrito na próxima seção.

\section{O Jogo UsabiliCity}

UsabiliCity é um jogo desenvolvido para Web que tem por objetivo apoiar o ensino das propriedades de usabilidade descritas na técnica Avaliação Heurística (AH). A técnica AH, proposta por Nielsen (1994), fornece um conjunto de diretrizes que orientam inspetores a encontrar problemas de usabilidade na interface. A Tabela 1 apresenta a listagem completa das heurísticas da técnica $\mathrm{AH}$ e sua descrição.

O jogo UsabiliCity tomou como base as propriedades de usabilidade descritas nas heurísticas da técnica AH (ver Tabela 1). Nesse contexto, a técnica AH foi escolhida como base visto que: (a) é uma técnica de inspeção de usabilidade muito adotada (Fernandez et al., 2011); e (b) é necessário que os inspetores entendam as propriedades de usabilidade avaliadas pela técnica de modo a melhorar seu desempenho durante a inspeção (Nielsen, 1994). Com o intuito de facilitar o entendimento das propriedades de usabilidade descritas na técnica $\mathrm{AH}$, no jogo, problemas típicos de usabilidade que podem ocorrer em um sistema são exemplificados por meio de analogias com problemas em uma cidade. Através do uso de analogias com situações do cotidiano, o jogo tenta ajudar o aluno a entender melhor quais são os problemas que uma determinada heurística pode ajudar a identificar. Estas analogias foram criadas por um analista e dois especialistas em usabilidade com mais de quatro anos de experiência no desenvolvimento de interfaces usáveis. A interface do jogo foi criada com base em ideias da primeira autora do artigo. O cenário e os personagens do jogo foram criados utilizando-se a ferramenta Corel Draw, para edição de imagens. Para programação da interação do jogo foi utilizado Html 5 e Java Script.

Foi criada uma história para envolver o aluno durante o jogo, de forma a tornar o aprendizado mais divertido. Nessa história, a cidade, chamada de UsabiliCity, é um lugar com muitos problemas na sua estrutura que dificultam a realização das tarefas 
diárias dos seus moradores (os Users). O aluno tem o papel de um inspetor (representado por um menino com uma lupa) que deve ajudar a identificar quem pode solucionar os problemas da UsabiliCity. A UsabiliCity é governada e organizada pelas dez heurísticas da técnica AH (Nielsen, 1994). O objetivo do jogo é descobrir quais heurísticas podem ajudar a encontrar os problemas descritos para reorganizar a cidade e torná-la um lugar melhor para os Users. A Tabela 1 apresenta as analogias que foram criadas para cada uma das heurísticas da técnica AH (1994).

\section{Tabela 1. Relação entre heurísticas (Nielsen, 1994) e analogias com problemas mostrados na cidade.}

\begin{tabular}{|c|c|c|}
\hline Heurística & Propriedades de Usabilidade Avaliadas & Analogia Aplicada no Jogo \\
\hline $\begin{array}{l}\text { Visibilidade do status do } \\
\text { sistema }\end{array}$ & $\begin{array}{l}\text { O sistema precisa manter os usuários informados sobre o que está } \\
\text { acontecendo, fornecendo um feedback adequado dentro de um tempo } \\
\text { razoável. }\end{array}$ & $\begin{array}{l}\text { Locais da cidade não possuem nome, desta forma os } \\
\text { habitantes não sabem onde estão. }\end{array}$ \\
\hline $\begin{array}{l}\text { Concordância do sistema } \\
\text { com o mundo real }\end{array}$ & $\begin{array}{l}\text { O sistema precisa falar a linguagem do usuário, com palavras, frases e } \\
\text { conceitos familiares ao usuário, ao invés de termos orientados ao sistema. } \\
\text { Seguir convenções do mundo real, fazendo com que a informação apareça } \\
\text { numa ordem natural e lógica. }\end{array}$ & $\begin{array}{l}\text { Os simbolos e palavras que são mostrados nas placas da } \\
\text { cidade não fazem sentido. }\end{array}$ \\
\hline $\begin{array}{l}\text { Controle e liberdade do } \\
\text { usuário }\end{array}$ & $\begin{array}{l}\text { Os usuários frequentemente escolhem por engano funções do sistema e } \\
\text { precisam ter claras saídas de emergência para sair do estado indesejado sem } \\
\text { ter que percorrer um extenso diálogo. O sistema deve, portanto, prover } \\
\text { funções "undo" e "redo". }\end{array}$ & $\begin{array}{l}\text { Há muitas ruas sem saida, o que dificulta a circulação dos } \\
\text { veiculos. }\end{array}$ \\
\hline Consistência e padrões & $\begin{array}{l}\text { Os usuários não precisam adivinhar que diferentes palavras, situações ou } \\
\text { ações significam a mesma coisa. Seguir convenções de plataforma } \\
\text { computacional. }\end{array}$ & $\begin{array}{l}\text { Há sinais de trânsito diferentes (fora do padrão) em vários } \\
\text { locais da cidade, deixando os Users confusos. }\end{array}$ \\
\hline Prevenção de erros & $\begin{array}{l}\text { É melhor que o sistema possua um design cuidadoso que previna o erro antes } \\
\text { dele acontecer. }\end{array}$ & $\begin{array}{l}\text { Quando há obras na cidade, nunca são colocados avisos } \\
\text { para evitar acidentes. }\end{array}$ \\
\hline $\begin{array}{l}\text { Reconhecer ao invés de } \\
\text { lembrar }\end{array}$ & $\begin{array}{l}\text { O sistema deve tornar objetos, ações e opções visíveis. O usuário não deve ter } \\
\text { que lembrar informação de uma para outra parte do diálogo. Instruções para } \\
\text { uso do sistema devem estar visíveis e facilmente recuperáveis quando } \\
\text { necessário. }\end{array}$ & $\begin{array}{l}\text { As prateleiras do supermercado e das lojas não possuem } \\
\text { nomes indicando o que é vendido em cada seção da loja, } \\
\text { desta forma, toda vez que o habitante da cidade volta ao } \\
\text { local tem que lembrar onde se localiza o que ele deseja } \\
\text { comprar. }\end{array}$ \\
\hline $\begin{array}{l}\text { Flexibilidade e eficiência } \\
\text { de uso }\end{array}$ & $\begin{array}{l}\text { Os usuários novatos se tornam peritos com o uso. O sistema deve prover } \\
\text { aceleradores de formar a aumentar a velocidade da interação. O sistema deve } \\
\text { permitir aos usuários experientes "cortar caminho" em ações frequentes. }\end{array}$ & $\begin{array}{l}\text { Na cidade é preciso fazer caminhos muito longos para } \\
\text { chegar a um local, a cidade não possui atalhos. }\end{array}$ \\
\hline $\begin{array}{l}\text { Estética e design } \\
\text { minimalista }\end{array}$ & $\begin{array}{l}\text { Os diálogos não devem conter informação irrelevante ou raramente } \\
\text { necessária. Qualquer unidade de informação extra no diálogo irá competir } \\
\text { com unidades relevantes de informação e diminuir sua visibilidade relativa. }\end{array}$ & $\begin{array}{l}\text { Na cidade há nomes de locais muito detalhados sem } \\
\text { necessidade. }\end{array}$ \\
\hline $\begin{array}{l}\text { Ajudar os usuários a } \\
\text { reconhecer, diagnosticar e } \\
\text { corrigir erros }\end{array}$ & $\begin{array}{l}\text { As mensagens de erro devem ser expressas em linguagem clara (sem códigos) } \\
\text { indicando precisamente o problema e construtivamente sugerindo uma } \\
\text { solução. }\end{array}$ & $\begin{array}{l}\text { Quando ocorre um problema (como um incêndio), não há } \\
\text { um bom serviço de bombeiros disponivel para ajudar na } \\
\text { recuperação dos prédios. }\end{array}$ \\
\hline Ajuda e documentação & $\begin{array}{l}\text { É necessário prover ajuda e documentação embora seja melhor um sistema } \\
\text { que possa ser usado sem documentação. Essas informações devem ser fáceis } \\
\text { de encontrar, focalizadas na tarefa do usuário e não muito extensas. }\end{array}$ & $\begin{array}{l}\text { Não há um serviço de ajuda para o User saber onde pode } \\
\text { obter determinado documento ou serviço. }\end{array}$ \\
\hline
\end{tabular}

A Figura 1 apresenta a tela do jogo que apresenta a história ao jogador, e a tela que mostra a Usabilicity, onde o jogador deverá selecionar qual fase irá jogar. No início do jogo, apenas a fase inicial está habilitada (uma fase está habilitada quando o número da fase está em vermelho). Conforme o jogador for concluindo as fases, ele terá acesso às próximas fases do jogo, totalizando cinco fases. Caso o jogador queira, ele poderá revisitar as fases que já concluiu.

A Figura 2 mostra como o aluno joga cada fase do jogo UsabiliCity. Ao acessar uma fase, o jogo apresenta uma tela como a da Figura 2 Parte A. Nesta parte da figura, o Elemento 1 indica $o$ número da fase $\mathrm{e} o$ título da fase em termos de problemas/propriedades típicos de usabilidade. Já o Elemento 2 apresenta a descrição dos problemas presentes na cidade que devem ser resolvidos na fase do jogo. Em cada fase são descritos dois problemas distintos. Para cada um dos problemas, o jogador deve selecionar uma heurística que será a responsável pela sua solução. Finalmente, no Elemento 3 são apresentadas as heurísticas para seleção pelo jogador. Para chamar a atenção do jogador, as heurísticas são representadas em forma de personagem. 
Durante o jogo, o aluno deve selecionar as duas heurísticas adequadas que ajudam a identificar os problemas descritos na fase corrente. $\mathrm{O}$ aluno pode checar a descrição da heurística como mostra a Figura 2 (Parte B), pois ao passar o mouse sobre uma heurística, é apresentado um balão informando que tipo de problemas essa heurística ajuda a encontrar na interface. Quando o aluno tiver certeza das heurísticas que podem ajudar a resolver um problema na UsabiliCity, este pode selecioná-las clicando nelas (ver Figura 2 Parte $\mathrm{C}$ ). O aluno pode selecionar apenas duas das dez heurísticas disponíveis em cada fase. Se o aluno quiser modificar sua resposta, ele pode reiniciar a fase. Finalmente, quando o aluno tiver certeza da sua escolha, pode validar sua resposta clicando no botão "ok" (ver Figura 2 Parte A). O jogo verificará se o aluno escolheu as heurísticas corretas, e se esse for o caso poderá passar para a próxima fase.

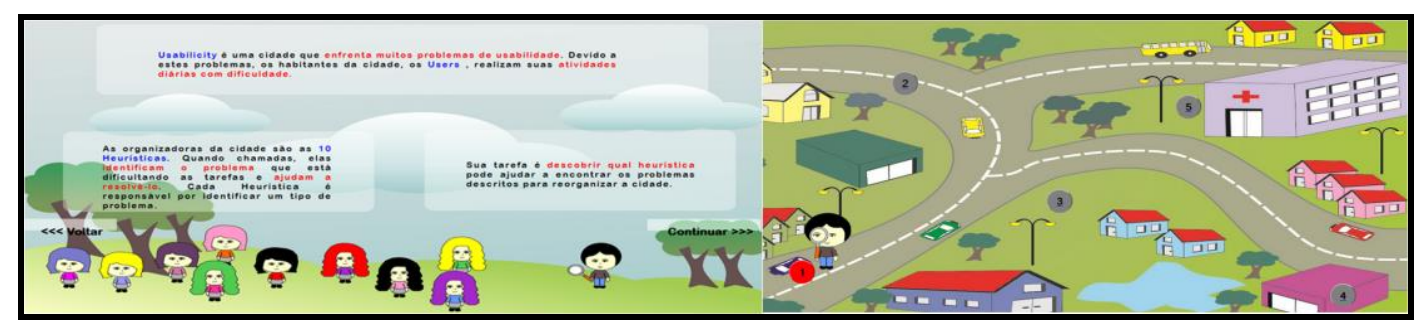

Figura 1. Tela de introdução do jogo (esquerda) e tela da UsabiliCity (direita).

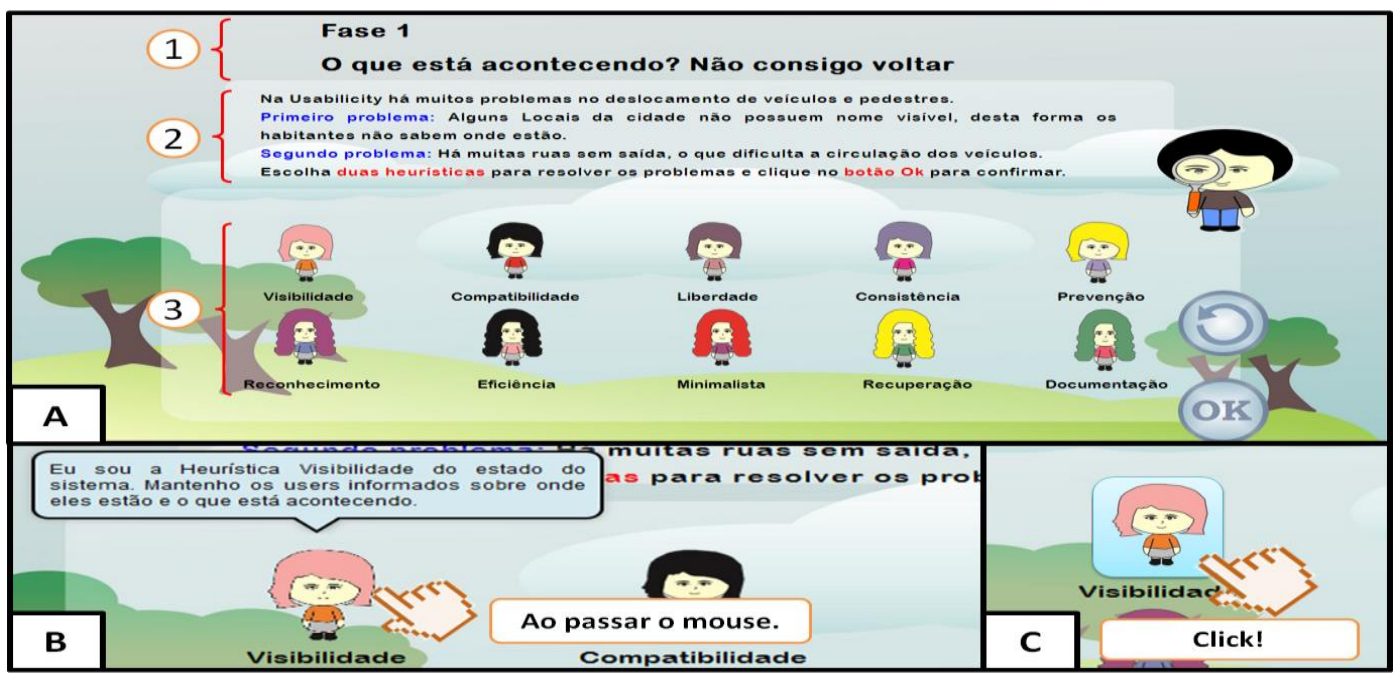

Figura 2. (A) Tela de uma das fases do jogo, (B) Dicas das propriedades de usabilidade avaliadas, e (C) Seleção da resposta.

Dependendo do seu desempenho em cada fase, o jogador pode visualizar mensagens de sucesso ou fracasso. Na tela de sucesso, ou seja, se o jogador conseguiu identificar todas as heurísticas da fase corretamente é mostrada a seguinte mensagem: "Parabéns! Você ajudou a resolver os problemas da cidade e deixou os users satisfeitos. Na próxima fase há um novo desafio para você.". Por outro lado, se o aluno errar uma ou duas heurísticas na fase, o sistema apresentará uma tela de fracasso com a seguinte mensagem: "Que pena! Você não chamou as heurísticas corretas para resolver o problema e a cidade virou um caso. Reveja qual é o papel correto de cada heurística e tente novamente." Nesse caso, o jogador ainda pode verificar as respostas da fase, o que leva o jogo a apresentar uma tela onde são indicados os motivos pelos quais uma determinada heurística foi escolhida para solucionar um problema. Desta 
forma, o aluno pode entender melhor para que tipo de problemas uma determinada heurística é mais adequada. Finalmente, quando o aluno conseguir finalizar todas as fases, o aluno será levado a uma tela de fim de jogo com a seguinte mensagem: "Parabéns! Você ajudou a resolver todos os problemas da cidade. Agora os users podem ter uma vida melhor!".

\section{Avaliação do Jogo}

Segundo An et al. (2013), é importante avaliar o jogo educacional para verificar se o mesmo atende os requisitos de usabilidade e pedagógicos necessários para o engajamento do aluno. Consequentemente foi feita uma avaliação em duas perspectivas: (a) do ponto de vista do professor e (b) do ponto de vista dos alunos. Desta forma, o estudo foi realizado em uma turma com 37 alunos do $5^{\circ}$ período do curso de Ciência da Computação do Centro Universitário do Norte, e com seu professor de Interação Humano Computador.

Para realizar a avaliação do jogo por parte dos alunos, foi utilizado o questionário da Escala SAM (Self Assessment Manikin) desenvolvido por Lang (1980) que permite avaliar a qualidade afetiva de uma interface. Por meio da Escala SAM, é possível avaliar três dimensões: (a) Satisfação (prazer/desprazer); (b) Controle (domínio da situação/ dominado pela situação); e (c) Motivação (calmo/excitado). A escala SAM foi escolhida visto que, segundo Vargas et al. (2014), é necessário avaliar a qualidade afetiva do jogo e como o mesmo pode motivar o aluno a continuar jogando. A Figura 3 apresenta a escala SAM para as três dimensões citadas acima.

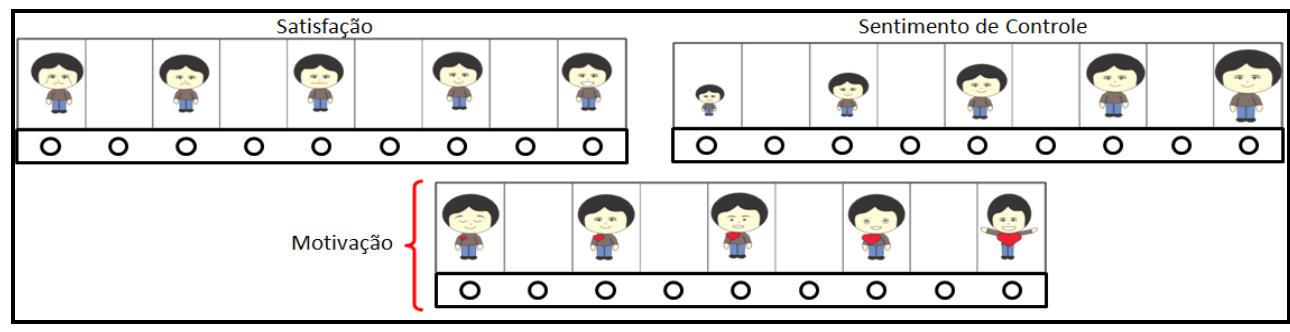

Figura 3. Escala SAM aplicada na avaliação do jogo por parte dos alunos.

Antes da avaliação do jogo, todos os alunos assistiram aulas sobre inspeção de usabilidade utilizando a técnica Avaliação Heurística (Nielsen, 1994) e assinaram um Termo de Consentimento Livre e Esclarecido (TCLE), onde concordavam em participar do estudo. A avaliação ocorreu em duas etapas: (a) utilização do jogo; e (b) preenchimento dos questionários. Durante a etapa de utilização, o aluno era convidado a jogar, e enquanto jogava, um observador tomava notas sobre: o tempo de interação do aluno com o jogo, as dificuldades encontradas e as reações do aluno em relação ao jogo. Após jogar, o aluno recebia o questionário da escala SAM (Lang, 1980) e uma explicação sobre como devia preenchê-lo. Para identificar oportunidades de melhoria no jogo de forma a aumentar sua qualidade afetiva, o observador verificava as respostas ao questionário SAM. Caso o aluno marcasse uma resposta negativa, o observador pedia para o aluno explicar a razão para a resposta e anotava estas informações para análise posterior. Este processo foi realizado como apoio ao questionário da escala SAM, para obter um feedback mais detalhado sobre a percepção dos alunos em relação ao jogo.O tempo médio de utilização do jogo pelos participantes foi de aproximadamente 11 
minutos, sendo o maior tempo identificado igual a 27 minutos e o menor tempo igual a 6 minutos, indicando que é viável a utilização do jogo durante uma aula sobre usabilidade. Para analisar os resultados da qualidade afetiva da interface, foram contabilizados os votos para cada tela avaliada, onde um voto é a alternativa que o aluno escolheu na escala SAM para cada dimensão. Foram avaliadas todas as telas do jogo, totalizando sete telas: (1) Introdução, (2) Seleção da Fase, (3) Fase, (4) Mensagem de Sucesso, (5) Respostas, (6) Mensagem de Fracasso, e (7) Fim do Jogo ao concluir todas as fases. Estas telas foram descritas na Seção 3. Para cada tela, os alunos aplicaram a escala SAM e seus votos foram classificados como: (a) negativos, votos marcados à esquerda da coluna central de cada uma das dimensões; (b) neutros, votos marcados na coluna central de cada uma das dimensões; e (c) positivos, votos marcados à direita da coluna central de cada uma das dimensões. Todos os pontos foram somados e contabilizados em um resultado geral. A Figura 4 apresenta os resultados para as dimensões do questionário SAM.

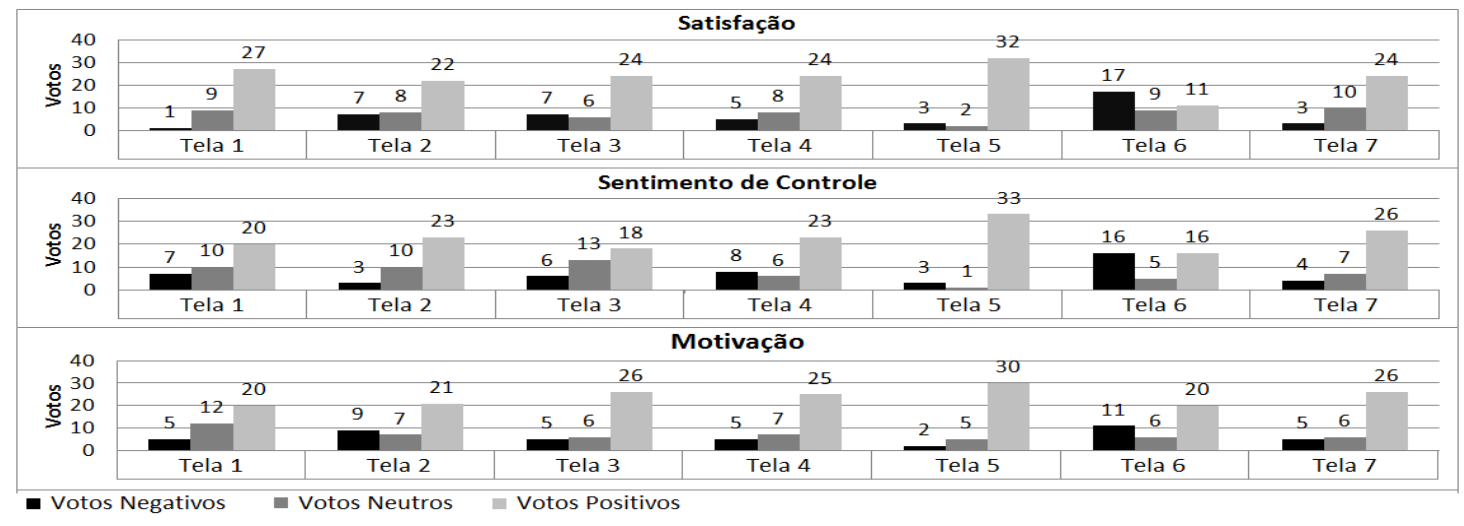

Figura 4 Votos das telas obtidos através do questionário SAM.

Sobre a satisfação dos alunos em relação ao jogo, os resultados foram positivos para todas as telas, exceto para a tela 6 apresentada na Figura 5, que teve 17 votos negativos, 9 votos neutros e 11 votos positivos. Em relação ao sentimento de controle, todas as telas continuam tendo a maioria dos votos positivos, ou seja, os alunos conseguiram ter controle do que estavam fazendo durante o jogo. Para a tela 6 houve empate com 16 votos negativos e positivos, e 5 votos neutros para o sentimento de controle. O resultado da avaliação sobre a motivação, houve o recebimento da maioria dos votos positivos, inclusive a tela 6 .

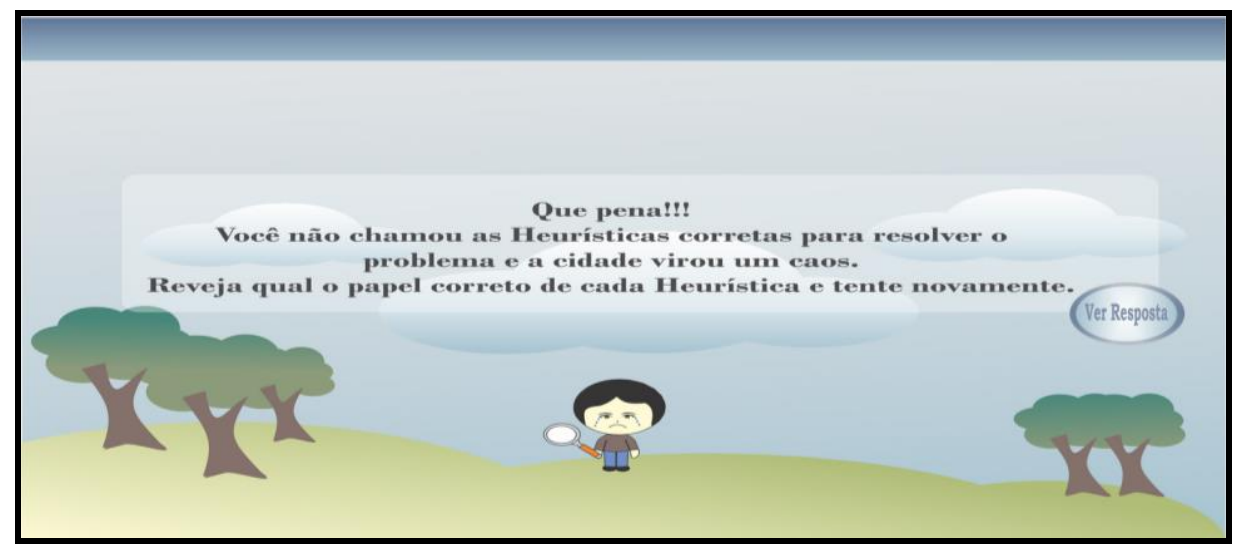

Figura 5 Tela apresentada quando aluno erra a fase 
A maioria dos resultados negativos para a tela 6 , em relação à satisfação e sentimento de controle, se deve ao fato da tela exibir uma mensagem de fracasso, quando o aluno não acerta as alternativas do jogo e tem que jogar a fase novamente; e que o aluno não pode tentar jogar a fase novamente sem ver as respostas. É interessante observar que apesar do resultado negativo obtido na satisfação e sentimento de controle para a tela 6 , o resultado da motivação foi positivo. Isso se deve ao fato de que alguns alunos se sentiam motivados a continuar jogando mesmo perdendo.

No geral mais de $75 \%$ dos votos foram positivos ou neutros, ou seja, os alunos se sentiram satisfeitos com o jogo, sentiram que estavam controlando o jogo como queriam e se sentiram motivados utilizando o jogo como ferramenta de aprendizagem. No entanto, para entender o que levou alguns alunos a votar de forma negativa $(25 \%$ restante), foram identificados problemas na interface com base nas observações durante o teste do jogo e/ou as respostas dos próprios alunos quando questionados. Alguns problemas identificados no jogo foram:

- Para alguns alunos não ficou claro como selecionar as respostas (indicar as heurísticas) nas fases.

- Alguns alunos não percebiam que deviam ser escolhidas duas heurísticas por fase.

- Alguns alunos acharam que a(s) tela(s) continha(m) muita informação.

- Para alguns alunos a fonte do texto e/ou cores não era agradável.

Para realizar a avaliação do jogo do ponto de vista do professor, foi aplicado o questionário de requisitos de usabilidade e pedagógicos sugerido por An et al. (2013). O questionário possui afirmativas que têm como possíveis respostas: atende plenamente, atende parcialmente, não atende e não se aplica. Além da aplicação do jogo em sala de aula, dois professores foram convidados a preencher o questionário e escrever suas considerações e/ou sugestões com o intuito de melhorar o jogo. A Tabela 2 apresenta o questionário aplicado com as respostas fornecidas pelos professores em termos dos requisitos de usabilidade e pedagógicos.

Tabela 2. Questionário de avaliação proposto por An et al. (2014) para avaliação do jogo UsabiliCity pelos professores.

\begin{tabular}{|c|c|c|c|c|}
\hline REQUISITOS & Atende & $\begin{array}{c}\text { Atende } \\
\text { Parcialmente }\end{array}$ & $\begin{array}{c}\text { Não } \\
\text { Atende }\end{array}$ & $\begin{array}{l}\text { Não se } \\
\text { Aplica }\end{array}$ \\
\hline \multicolumn{5}{|l|}{ Requisitos de Usabilidade } \\
\hline R1. A linguagem e é adequada ao público alvo definido e ao nível de ensino a que se refere. & 2 & & & \\
\hline $\begin{array}{l}\text { R2. O jogo é atrativo, envolvendo e cativando o aluno em sua utilização. O espaço é explorado e são } \\
\text { usadas múltiplas mídias (imagens, animações, vídeos, música etc). }\end{array}$ & & 2 & & \\
\hline R3. O tema é apresentado de forma lúdica e explora uma metáfora esclarecedora para o aluno. & 2 & & & \\
\hline R4. O jogo permite e incentiva a crescente autonomia e o envolvimento. & 1 & 1 & & \\
\hline $\begin{array}{l}\text { R5. O aluno consegue interagir com o jogo facilmente. Existe interação com outros usuários. As } \\
\text { interações são seguras e promovem os objetivos do jogo. }\end{array}$ & & 2 & & \\
\hline R6. Promove a criatividade (podem existem vários caminhos/respostas/soluções). & & 1 & 1 & \\
\hline R7. O tempo de cada ação é adequado. Existe a possibilidade de repetição. As etapas não são exaustivas. & 1 & & 1 & \\
\hline R8. As regras do jogo são coerentes e elas estão de acordo com o mundo imaginário proposto pelo jogo. & 2 & & & \\
\hline R9. O nível de concentração exigido está de acordo com o público do jogo. & 2 & & & \\
\hline \multicolumn{5}{|l|}{ Requisitos Pedagógicos } \\
\hline R10. O conteúdo é coerente e contextualizado com a área e o nível de ensino propostos. & 2 & & & \\
\hline $\begin{array}{l}\text { R11. O grau de dificuldade do programa é variável, podendo ser definido pelo aluno ou passando de } \\
\text { níveis de dificuldade menor para maiores, de acordo com os avanços obtidos. }\end{array}$ & & & 2 & \\
\hline R12. Aborda os conteúdos de forma a facilitar o aprendizado. & 2 & & & \\
\hline $\begin{array}{l}\text { R13. Oferece feedbacks construtivos, permitindo ao aluno identificar claramente quando acertou e } \\
\text { repensar suas ideias e estratégias quando não forem bem sucedidas Possui possibilidade de e } \\
\text { autocorreção. }\end{array}$ & & 2 & & \\
\hline $\begin{array}{l}\text { R14. O número de pontos obtidos é computado e é dado algum incentivo ou premiação ao se atingir } \\
\text { certos marcos, a fim de motivar o aluno. }\end{array}$ & 1 & & 1 & \\
\hline R15. Faz referência ao universo cotidiano dos alunos. & 1 & 1 & & \\
\hline
\end{tabular}


O jogo teve uma avaliação positiva em 12 dos 15 itens avaliados. Apesar de o jogo ser considerado uma boa ferramenta de aprendizagem, ainda existe a necessidade de melhorar alguns itens do jogo. É necessário aumentar o número de questões, e a dificuldade das mesmas. Além disso, é importante considerar problemas que possam ser resolvidos por mais de uma heurística de forma a exercitar a criatividade dos alunos. Dentre as recomendações dos professores na parte de considerações/sugestões de melhorias, foram citadas: (a) o uso de mais recursos como áudio e animações para aumentar o engajamento do aluno, (b) mudar as fases de forma a focar a atenção do aluno em uma heurística de cada vez, (c) após a solução dos problemas na UsabiliCity, trazer alguns problemas no contexto de desenvolvimento de software, (d) aumentar o número de problemas a serem resolvidos pelo aluno e sua dificuldade e (e) Modificar alguns problemas na interface do jogo (botões, cores, mensagens) para torna-lo mais fácil e agradável para os alunos.

\section{Conclusões e Trabalhos Futuros}

Este artigo apresentou o jogo UsabiliCity voltado para o ensino das propriedades de usabilidade descritas nas heurísticas da técnica $\mathrm{AH}$. Segundo os alunos que participaram da avaliação do jogo, o uso das analogias facilitou o entendimento das propriedades de usabilidade e o jogo foi percebido como divertido e motivador. Além disso, os professores que avaliaram os requisitos de usabilidade e pedagógicos do jogo deram um feedback positivo e um deles indicou que utilizaria o jogo novamente como instrumento pedagógico.

Apesar desta avaliação inicial positiva ainda existe a necessidade de incorporar melhorias no jogo, principalmente no aumento do número de fases. Para atingir os requisitos de usabilidade e pedagógicos é necessário criar novas fases com níveis diferenciados de dificuldade de forma a continuar engajando o aluno e motivá-lo a usar o jogo. Além disso, é necessário inserir problemas mais relacionados com a avaliação de sistemas de software dentro do contexto da própria UsabiliCity. Adicionalmente, o teste com os alunos e as respostas ao questionário SAM revelou a necessidade de solucionar alguns problemas de usabilidade de forma a melhorar a qualidade afetiva da interface. Será necessário repensar o processo de seleção das heurísticas em cada fase do jogo de forma a aumentar a experiência do usuário. Finalmente, para maior estímulo dos alunos enquanto eles estiverem tentando acertar a fase, a visualização das respostas será uma etapa opcional do jogo. Espera-se com isso que o aluno possa decidir se quer ou não continuar jogando até obter as respostas certas de uma determinada fase.

Como trabalho futuro pretende-se continuar a avaliação do jogo, porém com o foco no impacto do mesmo para a aprendizagem das propriedades de usabilidade, e também realizar uma avaliação do jogo com uma quantidade maior de professores para obter um resultado mais efetivo. Consequentemente, pretende-se replicar o estudo executado por Silva et al. (2010) em outras turmas do curso de Ciência da Computação, porém no contexto de conceitos de usabilidade. Para a futura execução do estudo, será realizado um comparativo do nível de aprendizado dos alunos quanto às propriedades de usabilidade em relação ao antes e depois do uso do jogo, de forma a verificar a eficácia pedagógica do mesmo. Espera-se desta forma desenvolver um jogo eficaz para o ensino de propriedades de usabilidade que motive os alunos e possa contribuir no ensino de usabilidade em cursos de computação no Brasil. 


\section{Agradecimentos}

Os autores agradecem a todos os participantes do estudo, aos professores que participaram da avaliação do jogo e aos monitores que colaboraram durante a execução do estudo. Finalmente, os autores agradecem o apoio financeiro do CNPq e da Fundação de Amparo à Pesquisa do Estado do Amazonas (FAPEAM) através do Edital $\mathrm{N}^{\circ}$ 016/2013, Projeto ProTI - Pesquisa sob o processo n. 062.00578/2014.

\section{Referências}

An, D., da Silva, C. , Ribeiro, D., da Rocha, P., Maltinti, C., Nunes, V., Fávero, R.: Digita-um Jogo Educativo de Apoio ao Processo de Alfabetização Infantil. Anais do Simpósio Brasileiro de Informática na Educação, 2013.

Barbosa, S., Silva B.: Interação Humano-Computador. Elsevier, 2010.

Benitti, F., Sommariva, L.: Investigando o ensino de IHC no contexto da computação: o que e como é ensinado?. Workshop sobre Ensino de IHC, 2012.

da Silva, T., Melo, J.: Cidade dos Bits: Um game para auxiliar no Aprendizado dos fundamentos da Ciência da Computação a Nível Médio. Anais do Simpósio Brasileiro de Informática na Educação, 2013.

Fernandez, A., Insfran, E., Abrahao, S.: Usability evaluation methods for the Web: A systematic mapping study. Information and Software Technology, Volume 53, Issue 8, 2011.

Lang, P.: Behavioral treatment and bio-behavioral assessment: computer applications. In: J. B. Sidowski, J. H. Johnson; T. A. Williams (Eds.), Technology in mental health care delivery systems. Norwood, NJ: Ablex, 1980.

Lopes, A. C.; Marques, A. B.; Conte, T., Avaliação do Jogo InspSoft: Um Jogo para o Ensino de Inspeção de Software. In: XII Simpósio Brasileiro de Qualidade de Software, 2013.

Nielsen, J.: Usability engineering. Morgan Kaufmann Pub, 1994.

Oeiras, J., Bentolila, D., Figueiredo, M.: Heva: uma ferramenta de suporte à avaliação heurística para sistemas web. VIII Brazilian Symposium on Human Factors in Computing Systems, pp. 136-145, 2008

Silva, R. Binsfeld, R., Carelli, I., Watanabe, R.: Automata Defense 2.0: reedição de um jogo educacional para apoio em Linguagens Formais e Autômatos. Anais do Simpósio Brasileiro de Informática na Educação, 2010.

Sommariva, L., Benitti, F., Dalcin, F.: UsabilityGame: jogo simulador para apoio ao ensino de usabilidade. 10th Brazilian Symposium on Human Factors in Computing Systems and the 5th Latin American Conference on Human-Computer Interaction. pp. 61-65, 2011.

Vargas, J., García-Mundo, L., Genero, M., Piattini, M.: A systematic mapping study on serious game quality. 18th International Conference on Evaluation and Assessment in Software Engineering, 2014.

Zyda, M.: From visual simulation to virtual reality to games. Computer, 38(9), 2005. 